\title{
El activismo de los pacientes trasplantados en la Argentina
}

\author{
Romero, Lucía Ana \\ El activismo de los pacientes trasplantados en la Argentina \\ CIENCIA ergo-sum, vol. 25, núm. 2, julio-octubre 2018|e11 \\ Universidad Autónoma del Estado de México, México
}

Esta obra está bajo una Licencia Creative Commons Atribución-NoComercial-SinDerivar 4.0 Internacional.

Romero, L. A. (2018). El activismo de los pacientes trasplantados en la Argentina. CIENCIA ergo-sum, 25(2). https://doi.org/10.30878/ces.v25n2a1 


\title{
El activismo de los pacientes trasplantados en la Argentina
}

\author{
Transplanted patients' activism in Argentina \\ Lucia Ana Romero \\ Universidad Nacional de Quilmes, Argentina \\ luromero19@gmail.com
}

Recepción: 10 de marzo de 2017

Aprobación: 25 de mayo de 2017

\begin{abstract}
Resumen:
Se analiza la organización de los pacientes trasplantados a través del accionar del Consejo Asesor de Pacientes (CAP) del Instituto Nacional Central Único Coordinador de Ablación e Implante (INCUCAI) de la Argentina. Se caracterizan los modos de construcción de credibilidad, las redes de experticia trazadas y los tipos de identidad que lograron conformar. Se concluye que este caso, como parte de una dinámica más general de la ciencia y la medicina contemporáneas en la que ambas son cada vez más interpeladas por públicos no especialistas, ha mostrado cómo los enfermos construyeron una identidad institucional a través de su membrecía en el CAP e identidad política a través del diseño e impulso de una ley propia.
\end{abstract}

Palabras Clave: trasplantes, conocimientos expertos, legos, participación ciudadana.

\section{Abstract:}

This paper analyses the organization of transplanted patients, observing the Consejo Asesor de Pacientes (CAP) of the Instituto Nacional Central Único Coordinador de Ablación e Implante (INCUCAI) in Argentina. We characterize how they built credibility, expertise networks and identity. We conclude that this case is part of a more extended dynamic of contemporary science and medicine in which these are greater questioned by unspecialized public. This case also showed how patients built institutional identity through its membership at the CAP and political identity by the design and impulse of its own law.

KEYWORDS: transplants, expert, lay knowledge, citizen's participation.

\section{INTRODUCCIÓN}

Los trasplantes de órganos han dejado de ser excepcionales y desde hace tiempo se han convertido en prácticas sociales. Alcanzan un desarrollo notable desde el punto de vista de su regulación legislativa y estatal, su aceptación social, el éxito médico quirúrgico, que es garantizado por la mejora en las drogas inmunosupresoras (cuya función es impedir el rechazo del órgano), las pruebas de histocompatibilidad pretrasplante (las cuales miden la compatibilidad entre donante y receptor) y la organización de sistemas nacionales de procuración de órganos fortalecidos por el crecimiento de bancos de donantes y listas de espera (Fox y Swazey, 2009).

Haciendo un poco de historia, en nuestro país los trasplantes se mantuvieron dentro de las esferas de la ciencia y la salud, en sus instituciones, prácticas y grupos profesionales durante casi veinte años, tiempo en el que quedaron fuera del alcance de la regulación estatal (Romero, 2016). Gracias al desarrollo de las pruebas de histocompatibilidad y de las drogas inmunosupresoras hacia fines de 1970, la demanda de trasplantes y las cirugías exitosas aumentaron (Löwy, 1987). En este contexto, y ante el vacío legal y regulatorio que existía en la materia en el país, el Estado argentino comenzó a regular esta práctica. En 1977 se dictó la Ley 21.541 que dio nacimiento al Centro Único Coordinador de Ablación e Implante (CUCAI).

A pesar de su creación en los años setenta, fue en la década de 1990 cuando el organismo se consolidó. Garantizó un verdadero sistema de procuración y distribución de órganos, el cual dio también una mayor institucionalización de la relación del cuerpo médico con el Estado y del INCUCAI con los pacientes. En la década del 2000 aconteció un salto significativo para la institución, pues se construyó y consolidó un sistema federal de procuración. Además, se aprobó la Ley 26.066 que incorporó la figura del donante presunto, la cual establece que toda persona mayor de 18 años es considerada donante con excepción de 
quienes manifiesten su voluntad en contra. También se logró la articulación de medidas que facilitaron el ingreso de pacientes a la lista de espera (en 2010 se contabilizaron 349 pacientes renales en lista de espera, mientras que en 2014 esa cifra aumentó a 914 y en 2015 a 1219), así como el incremento de la capacidad de los sistemas provinciales de salud pública para el desarrollo de la evaluación pretrasplante y trasplante y la implementación en los organismos de procuración provinciales de la estrategia del Hospital Donante para desarrollar al máximo la capacidad generadora de donantes del sistema hospitalario argentino (CRESICentral de Reportes y Estadísticas del SINTRA). ${ }^{[1]}$

En todo este proceso de crecimiento y especialización funcional del INCUCAI se visibilizó también un proceso de institucionalización creciente de la participación de los pacientes y enfermos dentro del organismo. El Consejo Asesor de Pacientes (CAP) es muestra de ello, ya que se constituye como un espacio de gestión y toma de decisiones sobre los procesos asociados a la procuración, donación y trasplante de órganos. Es protagonista del impulso de la ley de protección integral de la persona trasplantada (Ley 26.982).

En este trabajo, a través de entrevistas a informantes claves y de documentación de archivo, se analiza el papel de los pacientes vinculados al problema de los trasplantes de órganos dando cuenta del accionar del Consejo Asesor de Pacientes (CAP) del INCUCAI. Se caracterizan los tipos de conocimientos movilizados, las vías de interacción con los burócratas, técnicos y médicos, los conflictos surgidos, el poder de injerencia de los pacientes en el ordenamiento del sistema de procuración y distribución de órganos. En suma, analizamos cómo han construido identidad y credibilidad ante sus pares y los profesionales y cuáles estrategias desplegaron en su desempeño institucional. A modo de resultados preliminares, podemos afirmar que este caso se enmarca dentro de dos procesos. El primero de más amplio alcance, ubicado dentro de los llamados procesos de democratización de la ciencia, es decir, de la mayor injerencia de actores no científicos en la construcción de agendas (Callon et al., 2001) y en la conformación de instancias de gobierno (Jasanoff, 1990; Funtowicz y Ravetz, 1993), mediante procesos de hibridación de conocimientos, que utilizan a su vez conocimientos tecnocientíficos, tradicionales, locales, empíricos y étnicos (Vessuri, 2004). El segundo, y en un sentido más específico, la visibilización de la comunidad de afectados en espera de un trasplante y de los pacientes trasplantados a través de su participación en el CAP da cuenta de la creciente porosidad entre las fronteras de la biomedicina y la sociedad, de los ámbitos de la política y de la ciencia (Gieryn, 1983) y del llamado advenimiento de pacientes expertos, una modalidad de involucramiento de los enfermos que apunta a construir un diálogo más de igual a igual con el médico tratante, donde son capaces de saber y decidir en cuestiones técnicas de su padecimiento y de los tratamientos vinculados (Epstein, 1995; Lafuente y Alonso, 2011; Pecheny et al., 2012). Los miembros del CAP, en alianza con técnicos, médicos, funcionarios del organismo, experimentaron procesos de expertización, en la construcción de la ley de protección integral de las personas trasplantadas y en la edificación de redes a la hora de lidiar con diversos frentes de conflictos.

\section{Discusiones Conceptuales SOBRe EL ACTIVISMO DE LOS PACIENTES}

En las últimas décadas, y en conexión con los cambios señalados en torno al aumento de la participación pública en la ciencia, ha surgido un renovado interés académico en el campo de las ciencias sociales, y en la sociología en particular, por estudiar las organizaciones de pacientes como sitios claves donde se intersectan prácticas de formación de identidades y formas de activismo sociopolítico.

Con una preocupación más de tipo filosófica y política, Novas (2006) entiende que las esperanzas de cura y tratamientos que desarrollan las asociaciones de pacientes tienen dimensiones biopolíticas dado que al interactuar con científicos, profesionales de la salud y autoridades políticas contribuyen a moldear la salud y el estado de bienestar de las poblaciones. También concibe las actividades que llevan adelante estas organizaciones (adquisición de conocimientos, apoyo financiero a la investigación, concientización social sobre una enfermedad especifica) como parte de una "economía política de la esperanza", en donde resulta central el modo a través del cual las asociaciones de pacientes promueven diferentes elementos (tales como las 
terapias genéticas, los tejidos, las células madres, la sangre, el ADN, los órganos) como biovalores que inciden en el direccionamiento de las agendas de investigación biomédica, en sus normas sociales de organización y de legitimación (como el advenimiento de bancos privados de células madres y la consecuente apropiación privada y mercantilización de tales biovalores).

El trabajo de Epstein (1995) constituye un punto de partida ineludible para las reflexiones conceptuales que ayudarán en este trabajo a enmarcar el papel de los enfermos en cuanto a a) su poder de agregación y representación institucional, $b$ ) los tipos de conocimientos puestos en juego e intercambiados entre ellos mismos, los médicos, los funcionarios-burócratas, $c$ ) su injerencia en la toma de decisiones sobre los tratamientos, d) su participación en la producción de conocimiento científico médico ye) sus modos de lograr credibilidad ante los médicos, funcionarios técnicos y burócratas de la institución y ante la sociedad en su conjunto.

Otro antecedente relevante para este trabajo es el de Callon y Rabeharisoa (1999) sobre el papel jugado por la AFM (Asociación Francesa de Distrofia Muscular) en la investigación médica sobre dicha afección en Francia. Aquí proponen pensar las asociaciones de pacientes en función del tipo de apoyo financiero que aportan a la investigación y, más generalmente, según las modalidades de las relaciones que establecen con el medio científico y médico. Identifican tres tipos de asociaciones: a) la asociación-auxiliar, $b$ ) la asociación de partenariado y $c$ ) la asociación-opositora. La primera puede asumir dos modalidades: a) la delegación pura y simple. Los enfermos (asumiendo su ignorancia) se entregan a los científicos y a los especialistas en la elección de las orientaciones de investigación, $b$ ) la asociación de enfermos se dota de los medios para adquirir los conocimientos necesarios para discutir con ellos. En la asociación de partenariado se verifica la reivindicación de la importancia de la experiencia de los enfermos en la cualificación de sus enfermedades y en la definición de las soluciones por ejecutar. La experiencia del enfermo es aquello que lo vuelve a la vez insoslayable (él sabe lo que significa vivir con la enfermedad) y diferente (sus necesidades dictadas por la intimidad que tiene con la enfermedad pueden ser diferentes a las que supone el médico). Por estas dos razones, el enfermo se encuentra en una posición de socio del médico. La tercera y última, la asociación-opositora, está en contra de toda intervención de la ciencia oficial a la que acusa de poner en juego la propia identidad de los enfermos.

A diferencia de los enfermos y pacientes portadores de VIH/SIDA, quienes contaban ya con un fuerte activismo asociado a la identidad gay, con incidencia en la toma de decisiones sobre los tratamientos y sobre el proceso mismo de producción de conocimiento científico, los enfermos trasplantados y en espera de un trasplante carecen de ese tipo de membrecía e identidad previa y externa a la misma enfermedad. No obstante, su fuerza de presión y agregación colectiva llegó a conformar asociaciones de pacientes en espera de trasplantes, en el país y también el CAP dentro del INCUCAI, que lograron incidir en la legislación de los derechos de los trasplantados y de los enfermos en lista de espera y en la gestión misma de la procuración de órganos. Su nula injerencia en las agendas de investigación sobre trasplantes se relaciona con el alto nivel de estabilización de la práctica de trasplantes que se ha alcanzado en la actualidad. Considerando estas diferencias se retoman para el artículo algunas interrogantes presentes en Epstein (1995) y Callon y Rabeharisoa (1999): ¿Cómo lograron los pacientes construir credibilidad ante los médicos, técnicos y burócratas del organismos y ante sus representados? ¿Han incorporado lenguajes y conceptos médicos de la enfermedad como estrategia de construcción de credibilidad? ¿Mediante qué procedimientos? ¿Cómo hicieron del CAP un espacio con autoridad dentro del INCUCAI y hacia fuera de la institución? ¿Muestran en algunos de sus rasgos elementos característicos de la asociación auxiliar, de partenariado u opositora?

En relación con el proceso de construcción de credibilidad por parte de los pacientes de VIH, Epstein (1995) muestra que han predominado cuatro tácticas distintas: a) la adquisición de competencia cultural, $b$ ) la representación política, $c$ ) la puesta en común de reivindicaciones epistemológicas y éticas y $d$ ) la toma de posición en disputas metodológicas preexistentes. La credibilidad de un sujeto o grupo es también el capital acumulado que resulta de la capacidad para enrolar seguidores detrás de sus reclamos. En este sentido, se le 
puede considerar un sistema de autoridad en términos weberianos en el que se combinan aspectos de poder, dependencia, legitimación, confianza y persuasión (Cozzens, 1990; Epstein, 1995).

Otro nudo conceptual que atraviesa esta indagación dado el protagonismo que asumen los enfermos y pacientes, es el relativo al carácter lego y experto del conocimiento puesto en juego por ellos. La primera decisión que tomamos fue distanciarnos de las visiones que tienden a construir una dicotomía entre experticia y conocimiento lego, que recae en un modelo de déficit cognitivo de la comprensión pública de la ciencia por el cual el conocimiento verdadero está en manos de los expertos y la ignorancia de los legos (Vessuri, 2004; Bucchi y Neresini, 2008; Arancibia, 2016). ${ }^{[2]}$ Contra esta visión, los pacientes en espera de un trasplante y aquellos ya trasplantados han aportado saberes "verdaderos" sobre su experiencia de la enfermedad, elllamado conocimiento local, propio, personal, lo que Collins llama experticia contribuyente, es decir, conocimiento sobre los fenómenos y hechos que hacen al problema práctico, que en nuestro caso sería la enfermedad y los modos de combatirla (tratamientos) (Collins y Evans, 2002) y en tanto "comunidad de afectados en varios sentidos han sido llamados a ser comunidades epistémicas" (Lafuente y Alonso, 2011: 147) porque su capacidad de acción ha dependido de su habilidad para apropiarse del conocimiento y de las nuevas tecnologías de información y comunicación. Para hacerse visibles, para que su mal sea reconocido como tal, tuvieron que dar cuenta de cierta experticia para identificar la naturaleza del problema y sus diferentes variables, enmarcarlo en narrativas verosímiles, movilizarlo por las redes pertinentes, hacerse de recursos jurídicos, litigar con alguno de los actores involucrados en el tema y aliarse con otros, adoptar lenguajes técnicos y hacerse creíbles y respetables al interior del INCUCAI y hacia afuera. Esto se aproxima mucho a lo que Collins y Evans (2002) llaman experticia interaccional.

Siguiendo a Arancibia (2016) resulta interesante notar que, si bien Collins y Evans aportan conceptos y enfoques que se distancian del modelo de déficit no dejan de poner el foco en la experticia como habilidades certificadas en propiedad de personas o grupos. Al hacerlo se pierden de analizar al fenómeno experticia como un proceso más que como una cosa que tiene una persona, los diferentes tipos de conocimientos involucrados sin tener al científico como principal marco de referencia (esto es, las contribuciones de los movimientos sociales, activistas, usuarios o ciudadanos al conocimiento experto y viceversa) y por ende soslayar la importancia de mantener una perspectiva simétrica entre los conocimientos expertos y legos. En este mismo sentido Vessuri (2004) nos recuerda que el concepto de experto produce una asimetría y desigualdad entre el científico y el lego, rasgo que domina en la cultura científica moderna y hace que los legos suelan llegar a cuestionarla en su valor de uso, en su empleo social y político, pero no en términos de sus valores últimos.

La contrapropuesta sería mirar la experticia como propiedad de una red y no de personas. Desde esta perspectiva, la diferencia entre quienes tienen habilidades certificadas y quienes no las tienen es menos importante que la modalidad bajo la cual una red de experticia es construida o cómo una ya existente es reconfigurada. Esto no implica restar importancia a los actores y a su agencia, sino introducir a todos los contribuyentes sin realizar distinciones a priori entre expertos y no expertos. En muchas controversias públicas y problemas sociosanitarios no encontramos comunidades de afectados puras por un lado y de expertos por el otro. En cambio, lo que sí existe son agrupamientos que tienen mezclados en sus filas expertos y legos (híbridos) (Arancibia, 2016).

\section{EL INCUCAI: UNA BUROCRACIA EXPERTA EN TRASPLANTES}

En sociedades complejas como las nuestras donde existen grandes poblaciones y gran cantidad de saberes y amenazas, la confianza tiende cada vez más a ser depositada en sistemas expertos (Giddens, 1993) capaces de regular y controlar las incertidumbres y los problemas a los cuales nos enfrentamos. ${ }^{[3]}$ En el caso particular de la enfermedad, y específicamente la enfermedad prolongada que amenaza con la muerte, el saber experto se convierte en una fuente de reducción de incertidumbres (Funtowicz y Ravetz, 1993). El INCUCAI puede, 
en este sentido, ser visto como un sistema experto, ya que reúne, gestiona y distribuye órganos y listas de donantes y receptores, por lo cual goza de un gran crédito social. En efecto, el Estado argentino delega en el INCUCAI la experticia de controlar la ablación y la distribución en la realización de trasplantes y garantizar la transparencia en tales procesos. La donación de órganos se lleva a cabo bajo estrictos controles de anonimato, de manera que se alienta a que el receptor nunca conozca el origen del órgano que le ha sido implantado y la familia del donante no sepa la identidad del receptor o de los órganos donados.

El carácter democrático, equitativo, igualitario y de acceso abierto de la información y de los procesos que realiza el INCUCAI se visualiza en los registros existentes en el Sistema Nacional de Información de Procuración y Trasplantes de la República Argentina (SINTRA). Si se accede a través de la web oficial, se puede obtener una enorme cantidad y variedad de información: número y tipo de trasplantes realizados, por fecha, hospital, provincia, listas de espera por tipo de trasplante, tipo de instituciones (públicas/privadas) habilitadas para estas prácticas. Este carácter abierto y de acceso público de los registros, procedimientos y datos del sistema contradice el carácter tradicionalmente cerrado, secreto o profesional de los sistemas expertos, mientras que lo abstracto e informatizado del sistema y sus procesos le otorga rasgos propios de un sistema "objetivo, imparcial, transparente, despersonalizado", como se espera y confía sean los sistemas expertos.

En el INCUCAI se elabora la confección y actualización permanente de las listas de espera de potenciales receptores, se coordina la distribución de órganos y tejidos para trasplante, se dictan normas para la habilitación de los establecimientos que realicen actos médicos comprendidos en la temática y para la autorización de los profesionales que los practiquen, se da asistencia a los organismos jurisdiccionales en el Programa Federal de Procuración, se realiza el seguimiento de los pacientes trasplantados con fines estadísticos, entre sus funciones principales (Informe de gestión del INCUCAI 2003-2015).

El hecho de que el Estado, a través del INCUCAI, sea el intermediario entre donantes y receptores de órganos supone que en el proceso de adjudicación de órganos intervienen solamente los servicios médicos que están acreditados por éste (son hospitales donantes, generadores de órganos, aquellos inscriptos en el INCUCAI, y centros de trasplantes los que los llevan adelante; los pacientes entran en lista de espera cuando un médico del equipo de trasplante inscripto en el INCUCAI lo inscribe en ella).

Otro rasgo del procedimiento protocolizado es el relativo a los criterios de selección de los pacientes que esperan ser intervenidos: a) la compatibilidad que existe entre los tejidos del donante y receptor (histocompatibilidad), $b$ ) el estado de emergencia donde está en claro el peligro de la vida de un paciente en lista de espera, $c$ ) la antigüedad en lista de espera y $d$ ) la ubicación regional (existe el esfuerzo porque los órganos procurados en una provincia sean para pacientes de la misma provincia). La selección es realizada automáticamente por el SINTRA (Sistema Nacional de Información de Procuración y Trasplante de la República Argentina) y los pacientes seleccionados y sus médicos son informados en el momento en que se inicia un operativo. Estos elementos le otorgan "objetividad, equidad, anonimato e imparcialidad" al proceso.

En este sistema no cualquier enfermo puede recibir un trasplante. El paciente debe seguir una serie de procesos (pretrasplante), además de una serie de análisis clínicos, que incluyen también evaluación psicológica y psicosocial. Según el resultado de dichos análisis, la aprobación médica y de la obra social o la financiación estatal, el paciente ingresará a la lista de espera. Además, para ser receptor de órganos es necesario tener un año de residencia en el país.

Por el lado de las condiciones que deben cumplir los donantes, existen diferentes cuestiones a atender. Aparte de que es baja la tasa de donantes declarados, no cualquier muerte se convierte en una oportunidad de trasplante. Para que alguien pueda ser donante se utiliza el criterio de muerte encefálica soportado en el daño cerebral total y permanente, pero cuyas funciones cardiovasculares son sostenidas artificial y tecnológicamente por medio del respirador artificial. ${ }^{[4]}$ Se suma a esto el hecho de que los donantes cadavéricos de órganos pueden ser únicamente aquellos individuos a quienes se les diagnostica muerte encefálica y se encuentran bajo tratamiento en Unidad de Terapia Intensiva (UTI) al 
momento del diagnóstico y son asistidos por vía artificial para mantener en funcionamiento el subsistema cardiorespiratorio (entrevista a operador de seguimiento de trasplantes, Dirección Científica Técnica del INCUCAI, 14 de septiembre de 2016).

Este conjunto de cuidados, procedimientos y requisitos ha hecho que el INCUCAI, desde la coordinación de comunicación, priorice en los últimos años como estrategia institucional el trabajo con los hospitales y su personal para aumentar y mejorar la procuración de órganos, esto es, la producción de donantes, antes que el trabajo de concientizar y difundir la donación en la sociedad. "Los muertos y posibles donantes cadavéricos se encuentran en las UTI y bajo estrictas condiciones y no tanto en la sociedad" (entrevista al coordinador de comunicación del INCUCAI, 19 de julio de 2016). ${ }^{[5]}$

\section{El activismo de los pacientes y La construcción de EXPERTiCias: el Consejo Asesor de Pacientes (CAP y la sanción de la ley de trasplantes}

El CAP (Consejo Asesor de Pacientes) nació en 1993 mediante la sanción de la Ley 21.493. Allí se establecía que en el ámbito del INCUCAI funcionarían dos consejos asesores honorarios: $a$ ) un consejo asesor de pacientes (CAP) integrado por pacientes pertenecientes a las organizaciones que representan a personas trasplantadas y en espera de ser trasplantadas y $b$ ) un consejo asesor integrado por representantes de sociedades y asociaciones científicas, las universidades, otros centros de estudios e investigación y organismos regionales o provinciales de naturaleza similar a este instituto, y un representante de cada región sanitaria de acuerdo con lo establecido por el Ministerio de Salud y Acción Social, incluyendo a la provincia de La Pampa dentro de la región patagónica, y un representante de la Municipalidad de la Ciudad de Buenos Aires (MCBA)(Ley 24.193, artículo 48). El primer consejo tomó cuerpo mientras el segundo, el de profesionales, aún hoy se encuentra inactivo.

Los principales objetivos del CAP son a) colaborar en la concientización de la población en favor de la donación de órganos y tejidos, $b$ ) participar en las actividades de apoyo psicológico de los pacientes, pre y postrasplantados y de su entorno familiar, $c$ ) intervenir en las actividades de fiscalización propias del INCUCAI, incluyendo la distribución de órganos tejidos y células, $d$ ) bregar por la optimización en el funcionamiento de los servicios asistenciales y de cobertura social de los pacientes pre y postrasplantados en todo el territorio nacional, $e$ ) vigilar el buen desarrollo del sistema de trasplante de órganos, $f$ ) elaborar y proponer proyectos tendientes a mejorar y modernizar las leyes que se relacionan con la problemática de la donación y el trasplante de órganos, $g$ ) peticionar al Ministerio de Salud y Acción Social auditorías constantes a los centros de diálisis y demás instituciones en donde exista obligación de llevar correcto registro de pacientes en lista de espera. Ante la eventualidad de encontrar alguna irregularidad, ya sea en forma personal o por denuncia de terceros, presentar ante el directorio del INCUCAI la intervención inmediata de los mismos y publicitar sus posiciones y resoluciones internas (Reglamento interno del CAP, decreto 512/95, Acta 09/2007).

Sus integrantes son pacientes trasplantados o en lista de espera que sean miembros de organizaciones no gubernamentales (ONG), asociaciones y fundaciones de pacientes y nombrados por el Ministerio de la Salud de la Nación. En estos casos tienen voz y voto y participan en las reuniones plenarias cerradas. Quienes no cuentan con tal designación, sí pueden hacerlo en el CAP, pero en las reuniones abiertas. De hecho, todo paciente y toda persona interesada puede hacerlo también: son integrantes y tienen voz, pero no voto. El funcionamiento del CAP cuenta con la figura de secretario (elegido por el mismo Consejo) quien coordina las reuniones, el temario del día, distribuye y hace respetar los turnos y el debido registro en actas de todo lo tratado. Se reúnen mensualmente en el INCUCAI, sede central, aunque se intenta rotar las reuniones periódicas por las diferentes provincias del país a lo largo del año (Reglamento interno del CAP, decreto 512/95). 
Hoy en día existen 28 ONG, de todas partes del país, abocadas al tema de trasplantes y la donación de órganos, cuyos miembros integran o participan en el CAP. Las ONG difieren en su naturaleza, misión y estilo. En una primera indagación encontramos dos grandes tipos: unas conciben a los trasplantes como "un regalo de la vida" (Fox y Swazey, 2009) y se concentran en esta forma de difusión y concientización hacia la sociedad. Acompañan en la lucha a casos individuales en espera de un trasplante o apoyan a personas ya trasplantadas que pelean por su medicación ante prepagas u obras sociales, generalmente vía la presentación de amparos judiciales. El otro tipo de ONG se distancia de esta clase de actuar porque apuntan a instalar una idea colectiva del problema al tratar de conformar una comunidad de donantes haciendo a un lado la lucha individual por los trasplantes. Se basan "en una economía de don expandido" y del procomún, esto es, dentro de los llamados bienes comunes -no privatizable, plausible de ser legislado como un bien colectivo, como por ejemplo el agua, el aire, el silencio, los órganos trasplantables- (Lafuente y Alonso, 2011: 150). Las concepciones y orientaciones de acción de este segundo tipo de ONG encuadran mejor con las que predominan dentro del CAP (entrevista a representante de ONG CC, 19 de agosto de 2016; entrevista a representante de ONG BB, 19 de agosto de 2016).

A partir de la observación en las reuniones mensuales del CAP, se pudo constatar que en la actualidad los temas más recurrentes, planteados por miembros e integrantes del Consejo, giran alrededor de los conflictos suscitados entre pacientes y las obras sociales por su incumplimiento en la provisión de medicación necesaria en las etapas del pre y postrasplante, así como también discusiones en torno al reemplazo de medicación genérica por medicación innovadora. Otra cuestión en la agenda presente es la insuficiente oferta pública de diálisis, su concentración en centros urbanos y su ausencia en zonas más periféricas, temas centrales para el caso de los trasplantes renales (la mayoría de los trasplantes son de este tipo). Otro tema en agenda es la necesidad de expandir la emergencia de Consejos de Pacientes en las provincias, y así lograr una suerte de descentralización del CAP (en la actualidad se han desarrollado en las provincias de Santa Fe, Tucumán, provincia de Buenos Aires, Jujuy y Ushuaia) (entrevista a secretario del CAP, 21 de septiembre de 2016).

Si bien se halla fuera de las funciones establecidas por resolución y reglamento interno del Consejo, otro eje de debate se suscitó alrededor de la incumbencia del CAP y del INCUCAI en el juicio y seguimiento de las conductas de los pacientes trasplantados, en cuanto a si se ajustan o no a cuidados saludables e higiénicos. Ante esto surgieron dos posturas: $a$ ) una que insistía en la idea relativa a considerar que alguien trasplantado estaba obligado, por usufructuar de un bien común, a rendir cuentas de su vida. De algún modo vivir con un órgano “prestado" le hacía perder grados de libertad y autonomía y se volvía más deudor de una comunidad. b) La otra postura contrariaba esta idea afirmando que el hecho de tener un bien común, un órgano trasplantable, no habilitaba a la comunidad a inmiscuirse en su vida, cuya gestión permanecía siendo individual y privada (observación de la reunión del CAP, 18 agosto de 2016). En algunos casos de personas trasplantadas la vivencia subjetiva de haber recibido un órgano ha generado en ellos diferentes actitudes: pregonar individual y colectivamente para todo beneficiario de un órgano mantener una vida sana y libre de excesos como homenaje (agradecimiento) rendido al donante y a la comunidad en su conjunto (a aquellos que aún esperan un trasplante y están enfermos) y a ejercer acciones de colaboración y participación en la cuestión, como modo de agradecimiento (entrevista a representante de ONG BB, 19 de agosto de 2016). Otros, sin juzgar las conductas de los trasplantados, se sienten comprometidos a devolver de algún modo el favor recibido, donde es visible la lógica del don, en términos de la dinámica de reciprocidad e intercambio que atraviesa a todo lazo social (Fox y Swazey, 2009; Flórez Medina, 2012) (entrevista a representante de ONG AA, 23 de agosto de 2016). En otros casos, la reacción ha sido la contraria: una vez trasplantados, muchos pacientes no quisieron volver a saber de ese tema y dejaron atrás las incertidumbres y penurias vividas en relación con la enfermedad (entrevista a paciente XP renal trasplantado, 9 de agosto de 2016).

Expuestas las características organizacionales y funcionales del CAP, resulta importante mencionar que éste no siempre fue el mismo a lo largo de los más de veinte años de existencia. En los primeros años su presencia en el organismo fue más de tipo formal, no siendo mucho más que un componente de su 
organigrama. Los pacientes no estaban incorporados a la mesa de la gestión del INCUCAI. A partir de 2006 asumió funciones más activas y propositivas gracias al impulso que le dio el organismo poniendo al frente de tal tarea al coordinador de comunicación social. Esta nueva membrecía y liderazgo fue crucial y un punto de inflexión en la historia y el dinamismo del Consejo (entrevista al Secretario del CAP, 21 de septiembre de 2016). Otro liderazgo importante y que también irrumpió en ese mismo momento ejerciendo hasta el día de hoy fue el del secretario del Consejo. De profesión abogado, y paciente renal trasplantado en 1999, durante 12 años estuvo al frente de la secretaría del CAP. Hasta la llegada de ambos, el CAP direccionaba su acción casi únicamente hacia el INCUCAI. En términos de intermediación en la gestión de reclamos de pacientes juntaba menos de una decena de personas, y lo hacía fundamentalmente, en la modalidad de denuncias. A partir de la incursión del coordinador de comunicación del organismo y el secretario, el CAP creció en número y comenzó a ampliar sus intereses e injerencias. Dejó de apuntar sólo al INCUCAI y pasó a trazar el mapa del resto de los actores responsables e implicados en alguna de las etapas de los trasplantes y la donación de órganos, profundizó el conocimiento sobre los derechos de los pacientes y comenzó a trabajar en la difusión y concientización social en estos nuevos frentes.

La conversión del CAP en un actor con injerencia y participación más activa y comprometida en el diseño, la gestión y la evaluación de las prácticas de trasplantes y de donación de órganos no nació únicamente de los pacientes, sino de la incursión de nuevos liderazgos, como las del secretario y del funcionario del INCUCAI. Fue gracias al impulso de ambos que el CAP tomó la identidad y credibilidad que goza actualmente. Este estilo de los liderazgos y la impronta que le pusieron al Consejo descansó más en los caracteres personales de estos funcionarios que en una pauta de acción institucional. De todos modos, como consecuencias no buscadas de la acción, el organismo logró, a través de este nuevo CAP, ampliar el espectro de sus interlocutores, distribuir entre ellos también las presiones y socializar los reclamos de los enfermos para así descomprimir su desempeño como único y principal responsable.

El diagnóstico realizado por el coordinador y el secretario del CAP fue que los pacientes tenían "experiencia" de los procesos, pero les faltaba "formación" (técnica) y adquisición de competencias culturales (Epstein, 1995). Lejos estaban de desempeñarse como una asociación auxiliar de segundo tipo o de partenariado (Callon y Rabeharisoa, 1999). A partir de este diagnóstico, el coordinador presentó para el CAP un proyecto de formación que consistió en una agenda de capacitación anual, en gestión institucional, y se ofertó a todas las ONG existentes en el país que estaban vinculadas al tema. En este proceso se detectaron falencias y vacancias de conocimiento e información sobre derechos de los pacientes, lo cual impulsó la realización de una campaña educativa.

La adquisición de competencias culturales para los miembros del CAP en tal sentido formó parte de una primera apuesta inicial (Epstein, 1995). En palabras del secretario, el cambio vino a partir del momento que "dejamos de gritar y enojarnos y pasamos a preguntar por qué; a preguntarle a los médicos epor qué esa y no aquella medicación?” (entrevista a secretario del CAP, 21 de septiembre de 2016). Ello derivó en que el Consejo pasara a instituirse como un espacio abierto a la comunidad, pero centrado en los problemas y el protagonismo de los pacientes. Si bien ésta fue siempre su misión formal de origen, en la etapa inicial el CAP había sido cooptado en parte por los presidentes de ONG, quienes restaban protagonismo a los pacientes (surgieron algunos conflictos en relación con los límites, fronteras de acción y sentido que tenían las ONG en el marco del CAP) (entrevista al coordinador de comunicación del INCUCAI, 19 de julio de 2016).

Una estrategia posterior del CAP fue la representación política (Epstein, 1995), vía el impulso de una nueva legislación que amparara la situación de las personas trasplantadas y en espera de un trasplante. Hasta ese momento este grupo de afectados había estado regido por la ley de discapacidad. El disparador del cambio y de la idea de conseguir una ley propia fue a partir de 2003 cuando empezaron a verse cuestionados en su calidad de discapacitados. El Servicio Nacional de Rehabilitación (SNR) y gran parte del enfoque médico comenzó a visualizar al trasplantado como alguien que, al recibir un órgano, debía conceptualizarse como una persona capaz de trabajar, saludable y con una vida plena en general. Pero el paciente trasplantado a 
la vez no conseguía su alta médica por su estado de inmunosupresión, situación que, sin un marco legal propio que contemplara esta especificidad, lo colocaba en un estado de enfermedad permanente (entrevista a coordinador de comunicación, 19 de julio de 2016). Este clima de ideas implicó para la comunidad de trasplantados entrar en una suerte de limbo legal, en una zona gris e incierta que los colocaba en un frente de conflicto ante las obras sociales, las prepagas, los médicos y el Estado. La pérdida de cobertura legal y del marco de derechos y seguridades sociales, al dejar de ser reconocidos como discapacitados, suponía para los pacientes asumir costos económicos muy altos (dejar de percibir pensiones, reintegros de medicación, entre los más importantes). Ante esta amenaza, en el CAP se barajaron dos posibilidades: $a$ ) luchar por la reinserción en el marco de la ley de discapacidad o $b$ ) ir por la ley propia. Fue esta segunda opción la que ganó. La ley fue el fruto de un trabajo conjunto de miembros del Consejo: del coordinador de comunicación del INCUCAI y del protagonismo de un abogado y paciente trasplantado, hoy fallecido, quien materializó el proyecto de una ley propia para la persona trasplantada (entrevista a secretario del CAP, 21 de septiembre de 2016).

El proceso de diseño de la ley fue largo (se sancionó en 2013 y se reglamentó en 2015) y estuvo principalmente en manos de los miembros del CAP. Se hizo a imagen y semejanza de la ley de discapacidad (no posee muchas diferencias con ella). En efecto, la Ley 26.982 incluye la cobertura de $100 \%$ en la provisión de medicamentos, estudios diagnósticos y prácticas de atención del estado de salud de todas aquellas patologías que estén directa o indirectamente relacionadas con el trasplante, el derecho a viajar gratuitamente en los servicios nacionales de transporte terrestre de corta, media y larga distancia, oferta de programas de empleo y formación profesional por parte del Ministerio de Trabajo. En el caso de personas en situación de desempleo forzoso, y que no cuentan con ningún otro beneficio de carácter previsional, está previsto que puedan recibir una asignación mensual no contributiva equivalente a la pensión por invalidez a través de la Comisión Nacional de Pensiones Asistenciales del Ministerio de Desarrollo Social de la Nación (Ley 26.982).

Para la generación de esta ley y para su implementación la estrategia explícita de los miembros del CAP, aprendida a lo largo del proceso del crecimiento organizacional e institucional, consistió en construir redes de experticia mediante la activación de relaciones políticas y contactos profesionales fundamentalmente (Arancibia, 2016). Los miembros del Consejo buscaron el apoyo del anterior presidente del INCUCAI, quien ayudó a movilizar su capital social en la Cámara de Diputados y Senadores, y logró que algunos legisladores pusieran a disposición asesores propios para redactar y limar detalles del proyecto de ley.

En el proceso y en el documento final de la ley se aprecia la conjunción de conocimientos y argumentaciones jurídicas, médicas, experienciales, muchas veces implicadas entre sí o superpuestas entre sí. Por ejemplo, toda la discusión sobre una "ley propia", la consecuente diferenciación entre la situación del discapacitado y trasplantado ha mezclado argumentos médicos (la persona trasplantada es alguien sobre quien se intervino para volverla capaz), jurídico laborales (ambas figuras en caso de ser posible y deseable por el sujeto discapacitado o trasplantado merecen poder acceder a un trabajo digno), sociales (inclusión social, sujetos activos para la sociedad), experienciales o de conocimiento personal, local (el relato vivencial de la mayoría de los trasplantados ha sido coincidente con esta diferencia médica entre su condición y la del discapacitado en el sentido que aquellos después del trasplante "han vuelto a nacer", por dejar atrás los inconvenientes y padecimientos del estar enfermos y cambiar su calidad y estilo de vida, especialmente en los pacientes renales que dejan la diálisis). Este proceso de hibridación de tipos de conocimientos en la construcción de la ley da cuenta de procesos de apropiación y resignificación de los conocimientos cuando estos circulan entre distintos actores. Así, la hibridez no refleja sólo la variedad de intereses envueltos sino también el reconocimiento de la variedad de experticias (Vessuri, 2004).

Sumado a esta instancia coyuntural de la ley, en los conflictos cotidianos que los pacientes suelen mantener con las obras sociales y prepagas, por incumplimientos recurrentes en el suministro de medicación, la provisión de genéricos en vez de originales, han trazado alianzas estables con abogados quienes, a través de su experticia, han sabido recurrir al método de presentación de recursos de amparo (por ejemplo, ante la falta de entrega de medicación inmunosupresora por parte de una prepaga u obra social a un paciente trasplantado) 
que asegura una resolución inmediata a favor del paciente (los jueces ante la sola posibilidad de un riesgo de muerte no dudan en obligar a las prepagas u obras sociales a cumplir con lo solicitado por el paciente). Si bien el CAP no puede hacer tal presentación, al ser parte del Estado, lo puede impulsar a través de las ONG o personas en forma individual (como de hecho han procedido muchas veces). La mayor parte de las veces la judicialización de las causas conflictivas, vía la presentación de amparos, ha sido la vía más efectiva de su resolución. Esto se corresponde con el hecho de que el secretario del CAP por más de 10 años ha sido un abogado. Ante la experticia de la profesión médica (con sus tecnicismos, estimas sociales) los miembros del CAP antepusieron la experticia de la abogacía, con sus respectivas jergas técnicas y reconocimientos sociales que, si bien son diferentes a las de los médicos en contenido, no lo son en las formas. Guardan el prestigio de las profesiones y como tales el monopolio sobre algunos saberes muy especializados, al menos "en teoría" inalcanzables para el resto de los legos, no especialistas.

La construcción de confianza con sus representados, otros enfermos y pacientes individuales y agrupados en asociaciones, también operó como un elemento central para fortalecer su identidad y su credibilidad en las redes de experticia construidas por ellos. El CAP tiene la condición particular de ser un espacio de intersección entre los enfermos, sus asociaciones y el Estado. Sus miembros asumen dichos roles teniendo al mismo tiempo los intereses de los primeros y el distanciamiento requerido en tanto representante, miembro del CAP. En calidad de intermediarios entre los enfermos, los funcionarios del organismo (el Estado), las ONG, los médicos, las instituciones de atención, las obras sociales y prepagas, pero también en calidad de enfermos y pacientes, han logrado mezclar su experiencia y conocimiento personal de los padecimientos de la enfermedad, los cambios en los estilos de vida, las actitudes ambivalentes ante los tratamientos pre y postrasplantes, con los saberes técnicos, burocráticos y de gestión institucional aprendidos en el ejercicio del rol de miembro del CAP. En definitiva, su credibilidad se basa en que ellos cuentan con la ventaja de hablar los lenguajes vivenciales e íntimos de las enfermedades, los de tipo asociativo y los regulatorios estatales. Han ido adquiriendo estas tres identidades (pacientes-enfermos, representantes miembros del Estado, miembros de ONG) bajo lógicas de hibridación de conocimientos experienciales, asociativos y técnicos como el que manejan las ONG y de tipo burocrático y regulatorio estatal. Hacen de intérpretes y traductores de estos tres mundos (aunque muchos de ellos insisten en saber separarlos bien, interviniendo "personalmente" o hablando "en nombre de la ONG" dentro del CAP) y se vuelven "puntos de pasaje obligado" a la hora de gestionar sobre trasplantes en el país y con capacidades para movilizar redes de experticia al servicio de sus intereses.

\section{CONSIDERACIONES FINALES}

A lo largo de este artículo, se ha intentado pensar el crecimiento y el accionar del espacio de representación y participación de los pacientes trasplantados y enfermos en espera de un trasplante, el CAP del INCUCAI, como un proceso que se inserta en una dinámica más general de la ciencia y la medicina contemporáneas en la cual sus prácticas se ven interpeladas por públicos no especialistas como los enfermos, quienes comienzan así a debilitar los límites tradicionales que existían entre ciencia, medicina y sociedad (Gieryn, 1983; Epstein, 1995).

En el marco de estos procesos más generales, el análisis del espacio del CAP se centró en sus modos de construcción de identidad, en sus múltiples dimensiones (cognitiva, cultural, política, institucional, asociativa, experiencial), los proceso de hibridación de conocimientos puestos en juego, las estrategias defensivas y ofensivas de construcción de redes de experticia (de apropiación de experticias, de uso de estima profesional) y las apuestas de adquisición de competencias culturales y de representación política (Epstein, 1995). Así, los miembros de las ONG representantes de pacientes e integrantes del CAP lograron construir identidad institucional a través de su membrecía en el consejo dentro del INCUCAI e identidad política a través de la ley diseñada. Ambas identidades se asentaron en el aprendizaje técnico-médico, jurídico 
y burocrático de cuestiones ligadas a la práctica de trasplantes tales como las condiciones de ingreso y confección de la lista de espera, tests de histocompatibilidad, dosis y tipo de drogas inmunosupresoras, estudios médicos pretrasplante, procedimientos para iniciar operativos, infraestructuras médicas, derechos de pacientes, vías de reclamo ante obras sociales o prepagas, presentación de amparos, entre los más relevantes. La movilización política de estos conocimientos condujo en parte al diseño de la Ley 26.982, que trata su situación particular, diferente a la figura del discapacitado.

Asimismo, a lo largo de diez años supieron transformar su identidad y pertenencia institucional. Dejaron de ser vistos por los distintos funcionarios del organismo como un grupo de enfermos que se acercaban mensualmente al INCUCAI a beber café. Se transformaron en miembros de un consejo asesor que supo proyectar y diseñar una ley para la protección integral de la persona trasplantada movilizando relaciones de recursos políticos, sociales y profesionales (apelando a activar y hacer alianzas con legisladores, médicos trasplantólogos, abogados) para direccionar las agendas de las ONG y sostener redes de experticia como estrategia defensiva ante abusos, incumplimientos o fallas de algún engranaje del sistema. En términos conceptuales, esto implica poner el énfasis en el análisis de la experticia como parte de una red, de relaciones de recursos, antes que una propiedad que se tiene y, al mismo tiempo, supone adoptar una perspectiva que no define a priori quiénes son los legos y quiénes los expertos (Arancibia, 2016).

Es interesante notar que la participación más informada del CAP y su cambio de rol hacia un productor de hechos políticos se debió en parte al giro que le imprimió el organismo a través de la injerencia del coordinador de comunicación y también a la impronta personal que le dio la nueva gestión de la secretaría del consejo, activa en el mismo período y con grandes afinidades con aquél. A través de estas nuevas gestiones, el INCUCAI se quitó presiones y amplió los interlocutores del CAP, el cual a partir de entonces empezó a mirar e interactuar con otros actores del sistema. Asimismo, en esta evolución del consejo por la cual dejó de ser un conjunto de miembros de ONG y se fue convirtiendo en un consejo asesor de un organismo estatal como el INCUCAI, se fueron transformando identidades más de tipo combativas o de protestas (propias de las ONG) hacia otras más de tipo propositivas (como las que se esperan existan en un consejo asesor). No obstante, por momentos en el CAP persiste esa identidad de origen (ser miembros pacientes de ONG que interpelan al Estado) en algunos participantes y se generen ciertos roces con quienes reclaman un desempeño más de tipo institucional, propio de un miembro de un consejo asesor del Estado.

\section{ANÁLISIS PROSPECTIVO}

Este artículo ha dado cuenta de un caso de democratización de la ciencia y de participación pública en el campo biomédico en un país latinoamericano, contexto regional donde estos procesos en muchos casos se encuentran en ciernes. En el marco de una creciente apropiación del conocimiento científico y tecnológico por parte de la sociedad y de aumento de la incertidumbre, la ambivalencia y la desconfianza social hacia la ciencia y la tecnología, la relación entre expertos y legos es central para comprender estos procesos y para diseñar escenarios de interacción diferentes, tanto en el plano de los hacedores de políticas públicas como en el de organizaciones de la sociedad civil y de las instituciones científicas.

La centralidad otorgada a las habilidades y conocimientos movilizados por los pacientes trasplantados, en alianza con funcionarios del INCUCAI, pretende contribuir al cuestionamiento del enfoque tradicional con el que se comenzó a postular la necesidad de atender, tanto fáctica como normativamente, a la relación experto-lego. Dicho enfoque, presente muchas veces en abordajes analíticos como en propuestas de políticas, se ha centrado en un modelo de relación asimétrica y lineal basado en la concepción de la ausencia de formación científica del público (o déficit cognitivo), y que justificó la necesidad de políticas (públicas y corporativas) y de capacitarlo no sólo a través de las estructuras educacionales, sino fundamentalmente a través de lo que se denominó popularización de la ciencia y la tecnología. Los escasos logros alcanzados mediante tales acciones han llevado a replanteos de orientaciones de políticas y de abordajes conceptuales en 
torno al carácter lego del conocimiento, que intentan repensarlo en términos de todo lo que tiene (y no con base en lo que le falta) en calidad de conocimiento local, por experiencia y tradición e indagando en todos los procesos de apropiación, resignificación y traducción que en general hacen de los conocimientos expertos disponibles.

Este caso creemos que suma evidencia académica en este sentido, y aporta tanto para la discusión conceptual como para el diseño de políticas y de dispositivos organizacionales tendientes a incluir a los diferentes públicos (usuarios, pacientes, ciudadanos, campesinos, pequeños productores) en procesos de diseño, implementación y toma de decisión en torno a la ciencia y la tecnología, en carácter de agentes con saberes y puntos de vista con legítimos y variados sentidos que deben tomarse en consideración en la interacción con los conocimientos expertos.

\section{REFERENCIAS}

Arancibia, F. (2016). Rethinking activism and expertise within environmental health conflicts. Sociology Compass, 10(6), 477-490.

Bucchi, M. y Neresini, F. (2008). Science and public participation. The Handbook of Science and Technology Studies (third edition). Cambridge: The Mit Press.

Callon, M. y Rabeharisoa, V. (1999). Le Pouvoir des Malades, l'AFM et la Recherche. Paris: PEM

Callon, M., Lascoumes, P. y Barthe, Y. (2001). Acting in an uncertain world. An essay on technical democracy. Cambridge: The Mit Press.

Collins, H. y Evans, R. (2002). The third wave of science studies: Studies of expertise and experience. Social Studies of Science, 32(2), 235-296.

Cozzens, S. (1990). Autonomy and power in science, en S. Cozzens y Gieryn (eds), Theories of science in society (pp. 164-84). Bloomington: University Press.

CRESI (Central de Reportes y Estadisticas del SINTRA). Disponible en http://www.incucai.gov.ar/

Epstein, S. (1995). The construction of Lay Expertise: AIDS Activism and the Forging of Credibility in the Reform of Clinical Trials. Science, Technology \& Human Values, 20(4), 408-437.

Flórez Medina, A. (2012). Sin donante no hay trasplante. Una mirada al trasplante desde la reciprocidad (tesis de licenciatura). Buenos Aires: UNSAM.

Fox, R. y Swazey, J. (2009). The courage to fail. A social view of organ t RANSPLANTS AND DIALYSIS. New Brunswick: Transactions Publishers.

Funtowicz, S. y Ravetz, J. (1993). Science for the post normal age. Futures, 25 (7), 739-755.

Gibbons, M., Limoges, C. Nowotny, H., Schwartzman, S. Scott, P. y Trow, M. (1997). La nueva producción de conocimientos cientificos. La dinámica de la ciencia y la investigación en las sociedades contemporáneas. Barcelona: Ediciones Pomares-Corredor.

Giddens, A. (1993). Las consecuencias de la modernidad. Madrid: Alianza.

Gieryn, T. (1983). Boundary work and the demarcation of science from non-science: Strains and interest in professional ideologies of scientists. American Sociological Review, 48, 781-95.

Informe de gestión del INCUCAI (2003-2015). Instituto Nacional Central Único Coordinador de Ablación e Implante.

Jasanoff, S. (1990). The fifth branch: science advisers as policymakers. Cambridge: University Press.

Lafuente, A. y Alonso, A. (2011). Ciencia expandida, naturaleza común y saber profano. Buenos Aires: Universidad Nacional de Quilmes.

Lederer, S. (2008). Flesh and blood. Organ transplantation and blood transfusion in twentieth-century America. Oxford: Oxford University Press.

Lock, M. (2002). Twice dead. Organ transplants and the reinvention of death. 
Löwy, I. (1987). Choix scientifiques et choix éthiques dans le traitement de la maladie rénale terminale. Information sur les Sciences Sociales. Londres: Sage.

Novas, C. (2006). The Political Economy of Hope: Patients's Organizationes, Science and Biovalue. BioSocieties, 1, 289-305.

Pecheny, M., Manzelli, H. y Jones, D. (2012). Vida cotidiana con VIH SIDA y/o Hepatitis C. Diagnóstico, tratamiento y proceso de expertización. Serie Seminarios Saludy Política Pública. Buenos Aires: CEDES.

Pestre, D. (2005). Ciencia, dinero y política. Buenos Aires: Nueva Visión.

Reglamento interno del Consejo Asesor de Pacientes del INCUCAI. Decreto 512/95, Acta 09/2007.

Romero, L. (2016). Entre pipetas, bisturies y pacientes. La investigación clínica en la Argentina: la tradición Lanari. Buenos Aires: Biblos.

Shapin, S. y Schaffer, S. (2005). El Leviathan y la bomba de vacio. Buenos Aires: Universidad Nacional de Quilmes.

Vessuri, H. (2004). La hibridación del conocimiento. La tecnociencia y los conocimientos locales a la búsqueda del desarrollo sustentable. Convergencia, 11(35), 171-191.

\section{Notas}

[1] Véase CRESI: http://www.incucai.gov.ar/

[2] Asimismo, Funtowicz y Ravetz (1993) establecen que los asuntos que involucran riesgos ambientales y de salud son típicamente aquellos en los cuales los hechos son inciertos, los valores se encuentran en disputa y las decisiones son urgentes, propio de lo que llaman ciencia posnormal, siendo imposible separar los hechos de los compromisos valorativos que sostienen su producción. Lo anterior es motivo por el cual este tipo de ciencia posnormal requeriría de comunidades de pares extendidas de afectados, ya no por una razón de benevolencia sino de control de calidad y legitimidad. En términos de Collins y Evans (2002), el "problema de la legitimidad" se convirtió en el "problema de la extensión". Se disolvieron las fronteras entre ciencia y sociedad e involucraron nuevos públicos en los procesos de validación técnica. Gibbons et al. (1997) tienen otro aporte contemporáneo a las miradas que han proclamado la crisis de la ciencia disciplinar, autónoma y relativamente desligada de los presiones, demandas y apoyos de la sociedad, con el advenimiento de su denominado Modo 2, mientras que enfoques históricos como los de Shapin y Schaffer (2005) y Pestre (2005) han reivindicado desde siempre las tesis no demarcacionistas en relación con la ciencia.

[3] Los sistemas expertos son definidos como sistemas de logros técnicos o de experiencia profesional que organizan grandes áreas del entorno material y social respecto de los cuales los sujetos legos no tienen conocimiento, pero en donde depositan su confianza por la autenticidad del conocimiento experto que aplican (Giddens, 1993).

[4] El concepto de muerte cerebral y su institucionalización surgieron en el marco de las problemáticas planteadas por los trasplantes de órganos, tal como las controversias desatadas a la hora de decidir en qué momento un paciente asistido mecánicamente está muerto (Lederer, 2008). Desde fines de 1960 el criterio de muerte cerebral ha ido ganando espacio progresivamente en el mundo médico ante el criterio cardiopulmonar (Fox y Swazey, 2009), en el marco de la existencia de diferentes determinantes culturales a la hora de definir la muerte y de los procesos de aceptación social de los trasplantes de órganos en el mundo occidental (Estados Unidos) y oriental (Japón) (Lock, 2002).

[5] Los otros posibles donantes son los llamados vivo relacionado, familiares consanguíneos o relacionados en primer grado, o vivo consentido, aquel donante no familiar que acepta donar a una persona en particular por vínculos ajenos a los parentales. Últimamente, se han verificado también donantes cruzados, donde alguien dona un órgano a una persona, cuyo familiar o persona cercana dona a su vez al familiar o conocido del primer donante.

\section{BY-NC-ND}

\section{INFORMACIÓN ADICIONAL}

Una versión preliminar de este trabajo se presentó en el II Congreso Argentino de Estudios Sociales de Ciencia y Tecnología CAESCYT, desarrollado entre el 30 de noviembre y el 2 de diciembre de 2016. 